\title{
Effects of a Synthetic Peptide of a Parathyroid Hormone-related Protein on Calcium Homeostasis, Renal Tubular Calcium Reabsorption, and Bone Metabolism In Vivo and In Vitro in Rodents
}

\author{
Ashley J. P. Yates, Gloria E. Gutierrez, Peter Smolens," Philip S. Travis, * Michael S. Katz, Thomas B. Aufdemorte, ${ }^{\prime}$ \\ Brendan F. Boyce, Tazuko K. Hymer, James W. Poser, and Gregory R. Mundy \\ Divisions of Endocrinology and Nephrology, ${ }^{*}$ Department of Medicine, and Department of Pathology, ${ }^{\ddagger}$ University of Texas Health \\ Science Center at San Antonio, San Antonio, Texas 78284-7877
}

\begin{abstract}
A synthetic peptide corresponding to the first 34 amino acids of the parathyroid hormone-related protein (PTH-rP) produced by a human tumor associated with hypercalcemia was examined for skeletal and renal effects on calcium metabolism in vivo and in vitro. These effects were compared with those of human parathyroid hormone (1-34), hPTH (1-34). Equal doses of PTH-rP(1-34) and hPTH(1-34) produced equivalent stimulation of adenylate cyclase in vitro in bone cells and kidney cells and tubules. Subcutaneous injection of PTH-rP(1-34) in mice caused a significant dose-related increase in blood ionized calcium similar to that seen with hPTH(1-34) at equivalent doses. Repeated injections of equal doses of both peptides caused sustained hypercalcemia which was significantly greater in PTH-rP(1-34)-treated mice, although each induced comparable increases in histomorphometric indices of osteoclastic bone resorption. PTH-rP(1-34) and hPTH(1-34) also caused similar increases in bone resorption when incubated with fetal rat long bones in organ culture. Infusion of either peptide into thyroparathyroidectomized rats suppressed urinary calcium excretion and increased urinary excretion of cyclic AMP. PTH-rP appears to have similar effects to those of PTH on the skeleton, the kidney, and overall calcium homeostasis.
\end{abstract}

\section{Introduction}

Tumors associated with hypercalcemia often cause a syndrome which has similar characteristics to those of primary hyperparathyroidism. Thus, many cancer patients have increased renal tubular reabsorption of calcium (1-4), increased urinary excretion of cAMP $(5,6)$, and increased bone resorption (7-9). However, circulating concentrations of immunoreactive PTH are usually normal or suppressed in patients with hypercalcemia of malignancy $(5,10)$, and tumor tissues iso-

Address reprint requests to Dr. Mundy, Division of Endocrinology, Department of Medicine, University of Texas Health Science Center at San Antonio, 7703 Floyd Curl Drive, San Antonio, TX 78284-7877.

Received for publication 27 October 1987 and in revised form 16 December 1987.

J. Clin. Invest.

(C) The American Society for Clinical Investigation, Inc.

0021-9738/88/03/0932/07 \$2.00

Volume 81, March 1988, 932-938 lated from such patients have not been found to express significant amounts of messenger RNA for PTH (11). Recently, proteins with adenylate cyclase-stimulating activity similar to that of PTH have been partially purified from a variety of different human and animal tumor sources (12-14). Most recently, a tumor product with adenylate cyclase-stimulating activity derived from a human lung carcinoma cell line has been purified and partially sequenced, and the CDNA has been cloned $(15,16)$. This PTH-related protein (PTH-rP) ${ }^{1}$ has significant $\mathrm{NH}_{2}$-terminal sequence similarity with PTH. Independently, other workers have isolated proteins with apparent identity to PTH-rP at the $\mathrm{NH}_{2}$-terminal region from human carcinomas of breast, kidney, and lung (17-19). These studies suggest that a single protein may account for PTH-like activity in cancer patients. In this report we describe the biological effects in vitro and in vivo of a synthetic peptide consisting of the first 34 amino acids of this PTH-rP, PTH-rP(1-34), on bone and calcium homeostasis and compare these effects with those of human PTH(1-34), hPTH(1-34).

\section{Methods}

Materials. hPTH(1-34) was obtained from Bachem Fine Chemicals (Torrance, CA). PTH-rP(1-34) was synthesized by Peninsula Laboratories (Belmont, CA) according to the published sequence of Suva and colleagues (16) using the procedure of Hodges and Merrifield (20). This material was then purified to homogeneity by reversed-phase HPLC on a Vydac $\mathrm{C}_{18}$ column $(1 \times 25 \mathrm{~cm}$; Separations Group, Hesperia, CA) equilibrated with $0.1 \%$ trifluoroacetic acid and eluted using a gradient of $20-40 \%$ acetonitrile in $0.1 \%$ trifluoroacetic acid. The identity and purity of synthetic PTH-rP(1-34) was confirmed by amino acid and $\mathrm{NH}_{2}$-terminal sequence analysis.

Adenylate cyclase-stimulating activity. Adenylate cyclase-stimulating activity of the peptides was assayed in early passages $(<50)$ of the rat osteosarcoma cell line, UMR 106 (kindly provided by Dr. T. J. Martin, Melbourne, Australia). Adenylate cyclase activities of intact cells and of homogenates from confluent monolayer cultures of UMR 106 cells were measured as previously described $(21,22)$. Adenylate cyclase activity in homogenates of rat renal cortex and in isolated rabbit proximal straight tubule (PST) segments from rabbit nephrons was assayed under conditions described by Morel and colleagues for enzyme assay in PST (23). Dissected rat renal cortex $(0.5 \mathrm{~g})$ was homogenized in $10 \mathrm{ml}$ of $2 \mathrm{mM}$ Tris maleate buffer (containing $20 \mathrm{mM}$ $\mathrm{KCl}, 20 \mathrm{mM} \mathrm{NaCl}$, and $1 \mathrm{mM} \mathrm{MgSO}_{4} ; \mathrm{pH} \mathrm{7.6)}$ using three bursts of a

1. Abbreviations used in this paper: PTH-rP, parathyroid hormone-related protein; hPTH(1-34), human PTH comprising the first 34 amino acids of PTH. 
VirTis homogenizer (VirTis Co., Inc., Gardiner, NY) at a setting of 4.5. Isolated PST segments from rabbit nephrons were prepared and permeabilized according to the method of Morel and colleagues (23) except that kidneys were not perfused or incubated in collagenasecontaining solution prior to microdissection of the tubules.

Adenylate cyclase activities were expressed as nanomoles of cAMP per milligram protein/10 min in homogenates of UMR 106 cells and kidney cortex, as counts per minute $\left[{ }^{3} \mathrm{H}\right] \mathrm{cAMP}$ per well/10 min in intact UMR 106 cells and, in studies of rabbit PST, as picomoles cAMP per millimeter of PST/30 min.

Acute effects on ionized calcium in vivo. The acute in vivo hypercalcemic effects were tested in male Swiss mice (Charles River Breeding Laboratories, Inc., Wilmington, MA) weighing 25-34 g. Mice were injected subcutaneously either with vehicle alone $(1 \mathrm{mM} \mathrm{HCl}, 0.1 \%$ bovine serum albumin), hPTH(1-34), or PTH-rP(1-34) at doses of 0.3 , 1,3 , and $10 \mu \mathrm{g}$ of peptide in a volume of either 7.5 or $25 \mu \mathrm{l}$ delivered by Hamilton syringe (Hamilton Co., Reno, NV). The results of two experiments were combined. 10 mice received injections of vehicle alone (6 mice in the first experiment and 4 mice in the second), whereas each treatment group injected with peptide comprised 8 mice $(4$ mice in each of the two experiments). $40-\mu$ l blood samples were obtained by capillary tube (Ciba-Corning $\mathrm{Ca}^{+} / \mathrm{pH}$ capillary kit, Ciba Corning Diagnostics Corp., Medfield, MA) puncture of the orbital sinus before injection and at $60,150,240$, and 360 min thereafter. Whole-blood ionized calcium was measured using a Ciba-Corning $634 \mathrm{ISE} \mathrm{Ca}^{2+} / \mathrm{pH}$ analyzer which uses a sample volume of $35 \mu$. The calcium values were adjusted using the internal algorithm of the instrument to a $\mathrm{pH}$ of 7.4.

In vitro and in vivo bone resorption. The assay used to detect in vitro bone resorption has been described previously (24). Longer-term in vivo responses to $\mathrm{hPTH}(1-34)$ and $\mathrm{PTH}-\mathrm{rP}(1-34)$ were tested in male Swiss mice. Doses of $10 \mu \mathrm{g}$ of either peptide or vehicle alone (1 $\mathrm{mM} \mathrm{HCl} ; 0.1 \%$ bovine serum albumin) were injected four times each day at intervals of 4-8 h over a 3-d period (total of 12 injections). The injections, each of $25 \mu \mathrm{l}$, were given by Hamilton syringe into the subcutaneous tissues overlying the right side of the calvariae of six mice in each of the treatment groups. Orbital sinus blood was sampled before treatment and at $2 \mathrm{~h}$ after the second injection of each day for the 3-d duration of this experiment. In addition, blood was sampled just prior to the second injection ( $5 \mathrm{~h}$ after the first injection) on the third day and $10 \mathrm{~h}$ after the final injection immediately before the mice were killed (at $72 \mathrm{~h}$ ).

The effects on bone morphology were assessed in the calvariae which were removed intact from the mice at the end of the experiment. After fixation in $10 \%$ phosphate-buffered formalin, the occipital bone was removed by cutting immediately behind and parallel to the lambdoid suture using a scalpel blade. A 3-mm-wide strip of bone was then cut anteriorly to and parallel with the lambdoid suture, decalcified in $14 \%$ EDTA, dehydrated in graded alcohols, and embedded in paraffin. Four 3- $\mu \mathrm{m}$-thick representative, nonconsecutive step sections were cut and stained using hematoxylin and eosin.

The following variables were measured in two representative sections from each bone using a digitizing tablet and the Bioquant computerized image analysis system ( $R$ \& $M$ Biometrics, Inc., Nashville, TN): (a) total bone area (i.e., bone and marrow between inner and outer periosteal surfaces); $(b)$ the number of osteoclasts within the marrow cavity (expressed per square millimeter of the total bone area); (c) the extent of resorption, either active (with osteoclasts present) or total rough crenated surface, along the interface between bone and bone marrow (expressed as a percentage of the total length of this interface). These histomorphometric measurements were performed on the injected side of the calvariae at a magnification of 359 in the segment of bone between the sagittal suture and the muscle insertion at the lateral border of each bone. Seven consecutive fields of equal length were counted in each slide.

Urinary excretion of calcium and cAMP in rats. The effects of PTH(1-34) and PTH-rP(1-34) were examined in male Sprague-Dawley rats weighing 266-328 g obtained from Harlan Industries (Houston, TX). Rats were thyroparathyroidectomized using ketamine/xylazine anesthesia 48-72 h before study. Sodium and volume status was maintained by daily gavage with $15 \mathrm{ml}$ of $0.9 \%$ saline prior to the day of study. Adequacy of thyroparathyroidectomy was confirmed by an ionized blood calcium (from the orbital sinus) of $<1 \mathrm{mmol} /$ liter on the day before study. Under Inactin anesthesia $(100 \mathrm{mg} / \mathrm{kg}$ body weight; Promonta, Hamburg, Federal Republic of Germany), two catheters were placed into the left jugular vein for separate infusion of $100 \mathrm{mM}$ $\mathrm{CaCl}_{2}$ and Ringer's solution. The Ringer's solution contained $\left[{ }^{14} \mathrm{C}\right] \mathrm{in}-$ ulin (New England Nuclear, Boston, MA) for measurement of glomerular filtration rate (GFR) by standard techniques. A carotid catheter (PE-50) was used for blood sampling. A siliconized femoral venous catheter (PE-10) (both catheters from Intramedic, Becton, Dickinson \& Co., Parsippany, NJ) was used for infusion of the peptides or of vehicle alone ( $0.9 \%$ saline; $1 \%$ bovine serum albumin). A PE-50 catheter was placed in the urinary bladder and urine was collected under mineral oil. After preparation in this manner rats were given a bolus containing $1.3 \mu \mathrm{Ci}\left[{ }^{14} \mathrm{C}\right]$ inulin with subsequent infusion at $1.5 \mu \mathrm{Ci} / \mathrm{h}$. $\mathrm{CaCl}_{2}$ was initially infused at a rate of $1 \mathrm{ml} / \mathrm{h}$ until the blood ionized calcium (measured using the Ciba-Corning $\mathrm{Ca}^{2+} / \mathrm{pH}$ analyzer) increased from initial concentrations of $<1 \mathrm{mmol} / \mathrm{liter}$ to between 1.3 and $1.4 \mathrm{mmol} /$ liter. Thereafter the blood ionized calcium was maintained within or close to this range by adjustment of the calcium infusion rate based on 15-30-min blood calcium measurements.

After a stabilization period of $90 \mathrm{~min}$, seven consecutive $30-\mathrm{min}$ urine samples were collected together with midpoint $400-\mu$ l blood samples. To minimize blood loss the red blood cells were rapidly separated from the plasma, resuspended to original volume in Ringer's solution, and reinfused via a femoral venous catheter. Infusion of the vehicle was commenced at the initiation of the clearance periods and in the control rats $(n=5)$ was continued throughout the experiments at the rate of $400 \mu \mathrm{l} / \mathrm{h}$. In treated rats after two control 30-min urine collections, the vehicle infusion was replaced by infusion of either hPTH(1-34) $10 \mu \mathrm{g}(n=4)$ or PTH-rP(1-34) $10 \mu \mathrm{g}(n=4)$ in $400 \mu \mathrm{l}$ of vehicle infused over $1 \mathrm{~h}$

Urinary calcium was measured by atomic absorption (model 5000 , Perkin-Elmer, Norwalk, CT). Relative plasma and urine concentrations of $\left[{ }^{14} \mathrm{C}\right]$ inulin were measured in $10-\mu$ laliquots using a scintillation counter (LS 5000, Beckman Instruments, Inc., Palo Alto, CA). Urinary cAMP was measured in unextracted aliquots of rat urine by automated radioimmunoassay (25) using radioiodinated succinyl cAMP tyrosine methyl ester prepared as described by Brooker and co-workers (26). Urinary excretion of calcium was expressed in millimoles per milliliter of glomerular filtrate. Total urinary excretion of cAMP was expressed in nanomoles of cAMP per hour.

\section{Results}

The adenylate cyclase-stimulating activities of hPTH(1-34) and PTH-rP(1-34) in each of the assay systems tested were comparable (Fig. 1). The two peptides were equipotent in both UMR 106 assays (intact cell and cell homogenate) and in the renal cortical homogenate assay. Moreover, both hPTH(1-34) and PTH-rP(1-34) stimulated adenylate cyclase in rabbit PSTs, a site at which PTH is known to act (27).

Single subcutaneous injections of either hPTH(1-34) or PTH-rP(1-34) in intact mice induced significant hypercalcemic responses at $1 \mathrm{~h}$ with all doses of either test material between 0.3 and $10 \mu \mathrm{g}$ (Fig. 2). However, no significant hypercalcemic response occurred at any time point after injection of $0.1 \mu \mathrm{g}$ of either peptide in a single experiment $(n=4$ in each group; data not shown). Doses of $3 \mu \mathrm{g}$ or less of either peptide induced maximal hypercalcemia at $1 \mathrm{~h}$ with attenuation of this response thereafter, whereas the peak of the hypercalcemic response was more sustained after $10-\mu \mathrm{g}$ doses of either hPTH(1-34) or PTH-rP(1-34). At each dose the calcemic responses to the two peptides were similar. 

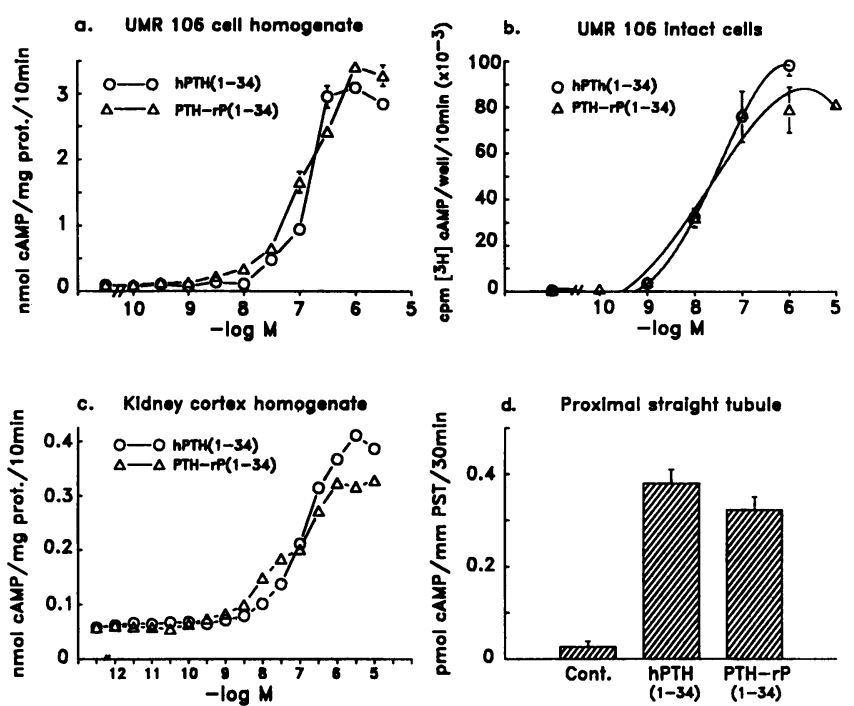

Figure 1. Effect of hPTH(1-34) and PTH-rP(1-34) on adenylate cyclase activity in four different in vitro assay systems. No differences in potency or efficacy were apparent between these peptides in UMR 106 homogenates $(a)$ or intact cells $(b)$, in rat renal cortical homogenates $(c)$, or in rabbit proximal straight renal tubules $(d)$. In the latter assay system tubules were exposed to hPTH(1-34) and PTH-rP(1-34) at a concentration of $10^{-7} \mathrm{M}$. Each bar represents the mean \pm SEM from three separate experiments in each of which adenylate cyclase activity was measured in two to six tubules for each treatment. Results shown in $a, b$ (mean $\pm \mathrm{SD}$ ), and $c$ (mean) are representative of two or more experiments in each case. In $a$ and $b$ error bars are absent where the range $\pm S D$ was too small to be depicted.

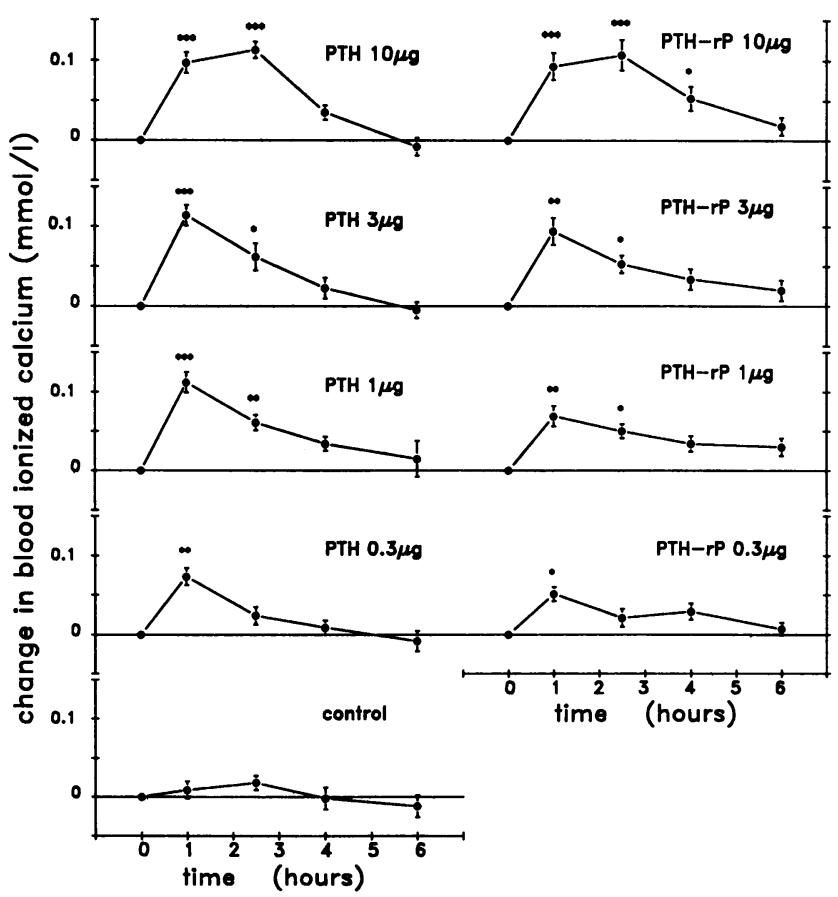

Figure 2. Acute effects of single injection of either hPTH(1-34) or PTH-rP(1-34) on whole-blood ionized calcium concentrations in mice. Each dose/treatment group contained eight mice. In each group, changes in calcium at each sample time were compared against values in controls $(n=10)$ at the same time point using Student's $t$ test for nonpaired samples. 1 , liter. ${ }^{*} P<0.05,{ }^{* *} P<0.01$, **** $P<0.0001$.
Both peptides were also tested for their effects on bone resorption using the fetal rat long bone organ culture system. In this assay, once again, the two peptides appeared to be equipotent (Fig. 3).

In preliminary studies we infused the two peptides either subcutaneously or intravenously by osmotic minipump (Alzet, Alza Corp., Palo Alto, CA). We observed rapid loss both of the hypercalcemic action and of the in vitro adenylate cyclasestimulating activity of PTH-rP(1-34) contained in the pumps. A previous study has shown a similar, although less marked, decline in activity of PTH in this infusion system (28). Unlike the authors of that study, we were unable to offset this loss of activity by siliconization of the pumps or increasing vehicle carrier protein concentrations (data not shown). It was for this reason that we chose to examine the effects of repeated injections of hPTH(1-34) and PTH-rP(1-34).

Repeated injections (four times daily for $3 \mathrm{~d}$ ) of either hPTH(1-34) or PTH-rP(1-34) induced progressive hypercalcemia which was particularly marked in samples taken $2 \mathrm{~h}$ after an injection (Fig. 4). However, blood ionized calcium remained elevated $5 \mathrm{~h}$ after the first daily injection on the third day $(51 \mathrm{~h})$ and immediately before killing, $10 \mathrm{~h}$ after the last injection ( $72 \mathrm{~h}$ ) (Fig. 4, inset). The increase in ionized calcium compared with controls was significant in both treated groups throughout the treatment period $(P<0.005$ at each sample time using nonpaired $t$ test). Interestingly, PTH-rP(1-34) produced significantly more marked hypercalcemia than did hPTH(1-34) $(P<0.05$ at each time point after $6 \mathrm{~h}$, Fig. 4$)$, a finding that was repeated in a subsequent experiment using different batches of both peptides (data not shown).

Bone histomorphometry showed similar increases in all indices of osteoclastic bone resorption within the calvariae in response to either hPTH(1-34) or PTH-rP(1-34) (Figs. 5 and 6). However, in addition, in the PTH-rP(1-34)-treated mice we saw as many osteoclasts on the outer periosteal surface as inside the bone on the injected side, a feature not observed in hPTH(1-34)-treated or control animals (Fig. 6). Osteoclastic bone resorption was also increased in sections taken through dorsal and lumbar vertebral bodies from hPTH(1-34)- and PTH-rP(1-34)-treated mice relative to control animals as well as in calvariae on the opposite side to the injection site (data not shown) indicating systemic effects of both peptides.

In rats infused with either hPTH(1-34) or PTH-rP(1-34), mean urinary excretion of calcium fell to a nadir of respectively $9 \%$ and $14 \%$ of baseline values near the end of the infusion period (Fig. 7). Urinary excretion of calcium increased

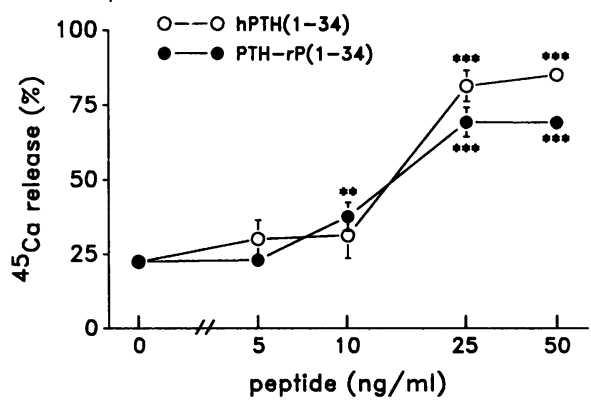

Figure 3. Bone resorbing activity of hPTH(1-34) and PTH-rP(1-34) in an in vitro fetal rat long bone assay at $120 \mathrm{~h}$. Values were compared against control values using Student's $t$ test for nonpaired samples. ${ }^{* *} P<0.02,{ }^{* * *} P<0.0001$. 


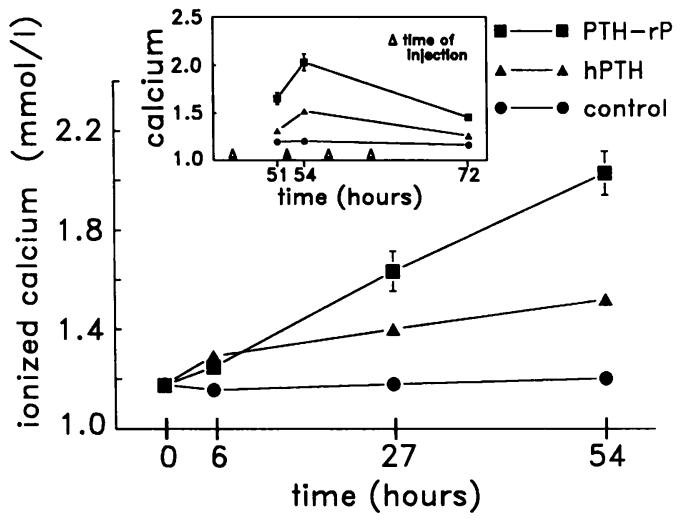

Figure 4. Whole-blood ionized calcium concentrations (mean \pm SEM) in mice injected with hPTH(1-34), PTH-rP(1-34), or vehicle alone. Injections were given four times daily for $3 \mathrm{~d}$. The main panel shows calcium values from samples obtained $2 \mathrm{~h}$ after the second injection of each day. The inset shows additional values obtained at 51 and 72 $\mathrm{h}$ ( $5 \mathrm{~h}$ and $10 \mathrm{~h}$, respectively from the time of the previous injection). Error bars are absent where the \pm SEM range was too small to be depicted. l, liter.

after the end of both treatments. Urinary cAMP excretion increased markedly and to a comparable extent in response to both peptides (Fig. 7). Changes in urinary excretion of calcium and changes in urinary excretion of cAMP followed a similar time course.

\section{Discussion}

The data reported here show that a peptide which is composed of the first 34 amino acids of the PTH-related protein associated with hypercalcemia of malignancy has similar biological activity to PTH both in vitro and in vivo. We have shown that this peptide, like PTH, stimulates adenylate cyclase in bone and kidney cells in vitro and increases urinary excretion of cAMP in vivo. Furthermore, we have demonstrated that PTH-rP(1-34) causes hypercalcemia in vivo, stimulates bone resorption both in vitro and in vivo, and increases renal tubular reabsorption of calcium. The major effects of both PTH and PTH-rP on target tissues, namely bone and kidney, were the same. However, our data do not exclude the possibility that

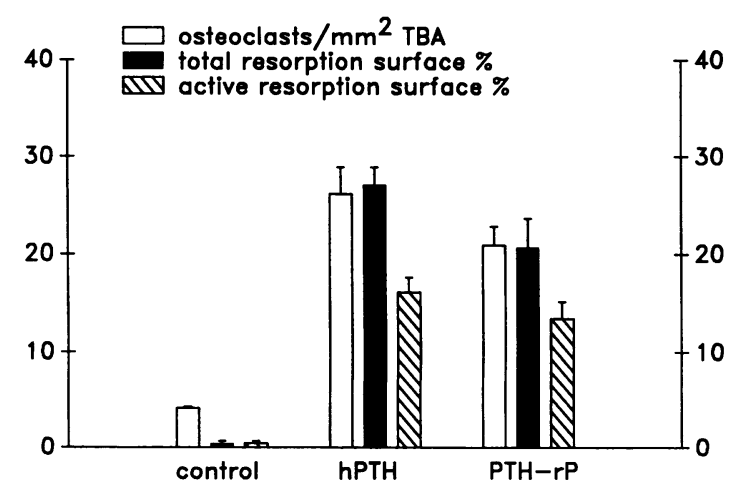

Figure 5. Effects of repeated injections hPTH(1-34) and PTH-rP(134) on indices of bone resorption in calvariae of mice. Resorption surfaces are expressed as a percentage of the total marrow-bone interface, and osteoclasts within bone are expressed as the number per square millimeter of total bone area (TBA). These measurements did not take account of periosteal bone resorption (see Fig. 6). there may be subtle differences between the two peptides. Indeed, some difference in activity is suggested by our experiments with repeated injections, in which PTH-rP(1-34) induced the appearance of periosteal osteoclasts on the injected side of the calvariae, an effect that we did not see in animals treated with hPTH(1-34). In addition the hypercalcemic response to PTH-rP(1-34) was clearly and reproducibly greater than that due to hPTH(1-34) (Fig. 4). The reason for this difference in the longer-term calcium changes is not apparent, although we speculate that differences either in the pharmacokinetics of the two peptides, or in the extent to which responses are downregulated may be important. Determination of the significance of these differences in response between the two peptides will require more detailed studies.

We have used several experimental techniques in these studies that have not been described previously. The new Ciba-Corning 634 ionized calcium/pH analyzer allows precise and reproducible measurements of ionized calcium on small volumes $(35 \mu \mathrm{l})$ of whole blood permitting frequent calcium measurements from individual mice. The ionized calcium concentration, unlike that of total serum calcium, is little influenced by changes in the concentrations of plasma proteins. In addition, ionized calcium more accurately reflects the ultrafiltrable fraction of plasma calcium than does measurement of total calcium. For these reasons ionized calcium is likely to be more useful than total calcium in studies of calcium homeostasis and of renal handling of calcium such as those performed here.

Our study of the effects of the peptides on renal tubular handling of calcium used a technique which we devised for these experiments. This technique enabled us to perform careful time-course experiments on the effects of the two peptides on urinary excretion of calcium and cAMP.

We have also used repeated injections of both peptides and quantified indices of osteoclastic bone resorption in vivo in addition to measuring changes in ionized calcium in whole blood. We chose to inject the peptides locally over the calvariae and to examine the underlying bone because our previous studies had indicated that basal levels of bone resorption at this site are low and that subcutaneous infusion of PTH and interleukin-1 (IL-1) (29) and local injection of IL-1 (Boyce, B. F., unpublished observations) cause an easily identified and marked increase in osteoclast numbers and resorption surfaces.

Two major questions concerning the biological effects of PTH-rP remain. First, what relative proportions of the hypercalcemic action of this protein can be attributed to its renal and skeletal effects? Secondly, what is the precise role of PTH$\mathrm{rP}$ in the production of hypercalcemia of malignancy? With regard to the first question, it seems likely, because of their rapidity, that the acute and transient effects of PTH-rP on hypercalcemia after a single injection are mediated by changes in renal tubular calcium reabsorption. In contrast, we have shown that the hypercalcemic effects of repeated injections of PTH-rP(1-34) (and hPTH(1-34)) are progressive and more sustained than those of single injections. At least part of this progressive hypercalcemia is likely to be related to the increased bone resorption that we observed. Although our data suggest that parallels with the established effects of excess PTH in primary hyperparathyroidism may be drawn, determination of the relative importance of the effects of PTH-rP on bone and the kidney will require further studies. 


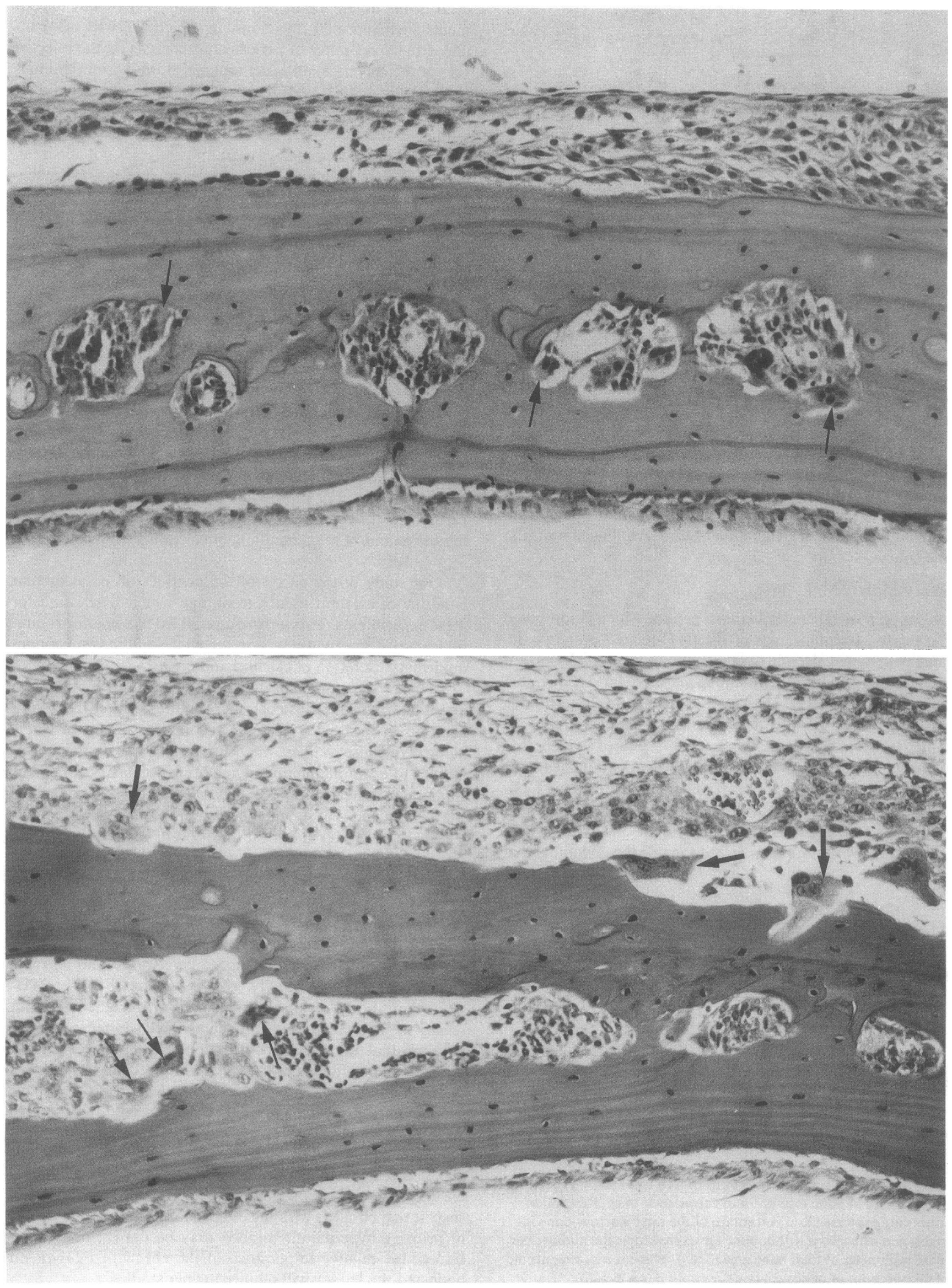




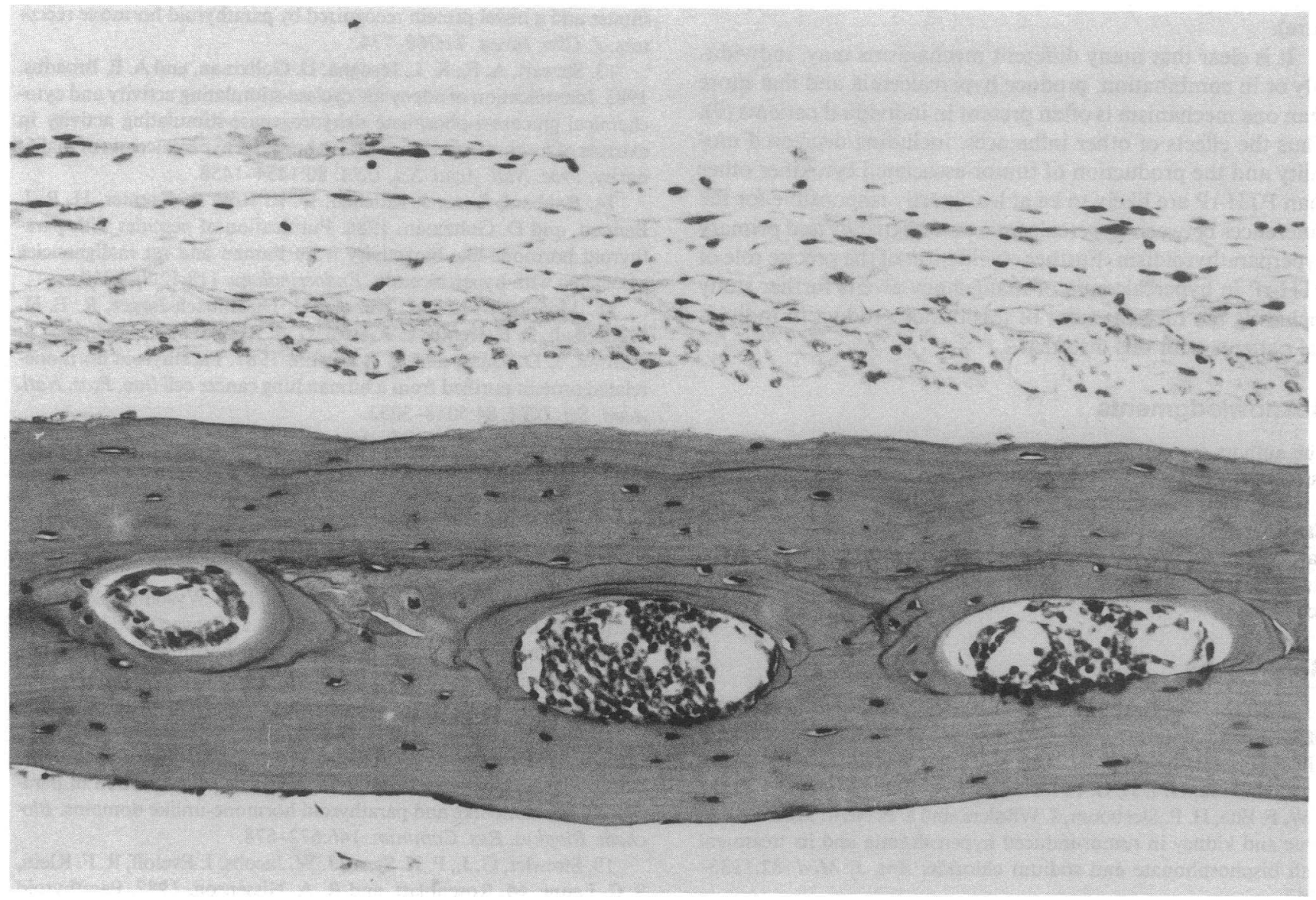

Figure 6. Histologic effects of hPTH(1-34) and PTH-rP(1-34) on mouse calvariae. Increased numbers of osteoclasts (small arrows) are seen resorbing bone along the bone/bone marrow interface in (opposite page) hPTH(1-34)-treated (upper panel) and PTH-rP(1-34)-
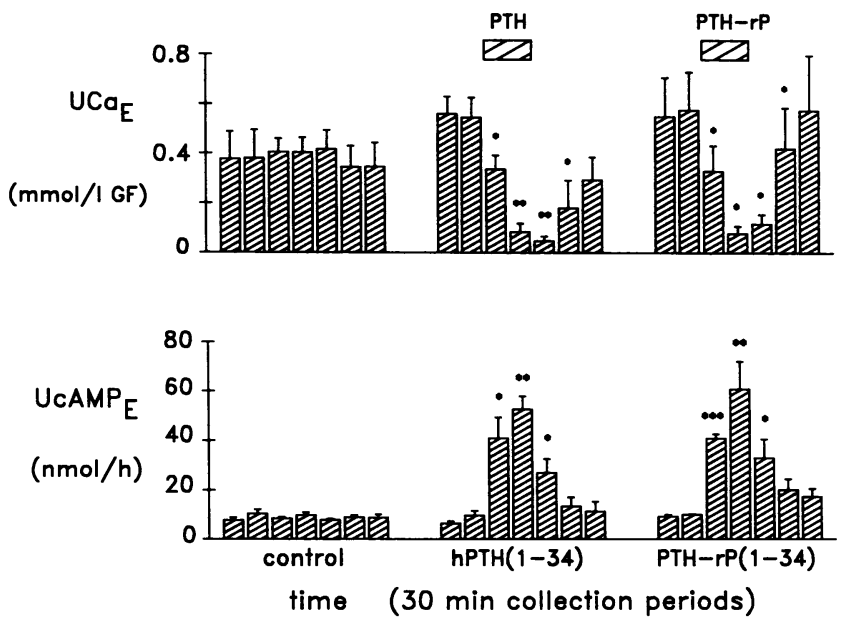

Figure 7. Urinary excretion of calcium ( $\mathrm{UCa}_{\mathrm{E}}$, expressed in millimoles calcium per liter [l] of glomerular filtrate [GF] and cAMP $\left(\mathrm{UcAMP}_{\mathrm{E}}\right)$ in control rats $(n=5)$ and rats infused over $1 \mathrm{~h}$ with hPTH(1-34) $(n=4)$ or PTH-rP(1-34) $(n=4)$. Values (mean \pm SEM) for each 30-min collection period were compared with those obtained during the second control collection period for each treatment group using Student's $t$ test for paired samples. ${ }^{*} P<0.05,{ }^{* *} P$ $<0.01,{ }^{* * *} P<0.0001$ treated (lower panel) mice in comparison with vehicle alone (above). In PTH-rP(1-34)-treated mice, multinucleate osteoclasts (large arrows) are resorbing bone along the periosteal surface. Hematoxylin and eosin stain.

The precise role of PTH-rP relative to other factors in the production of hypercalcemia of malignancy remains unclear. There is evidence that, as in primary hyperparathyroidism, many patients with hypercalcemia of malignancy have increased renal tubular reabsorption of calcium which is likely to be at least partly responsible for the hypercalcemia (1-4). Our data clearly indicate that PTH-rP is capable of mediating this effect. Bone resorption may also be increased in both primary hyperparathyroidism and in hypercalcemia of malignancy. However, there tends to be a greater relative increase of bone resorption over bone formation in the latter disorder $(7,8)$. Furthermore, serum concentrations of 1,25 dihydroxyvitamin $\mathrm{D}_{3}$ tend to be low in hypercalcemia of malignancy but are frequently increased in primary hyperparathyroidism (5). These differences between the two forms of hypercalcemia are not explained by the present study which indicates that PTHrP(1-34) and hPTH(1-34) share similar biological activities. One possibility to account for such differences is that the complete molecule, which comprises 141 amino acids, may prove to have a different range of biological activities from those we have shown. However, a different action, mediated through the PTH receptor, seems unlikely, particularly since the amino-terminal 1-34 portion of PTH has identical biological effects to those of the intact and complete 1-84 PTH molecule 
as well as the 1-34 portion of the PTH-rP molecule (as shown here).

It is clear that many different mechanisms may, individually or in combination, produce hypercalcemia and that more than one mechanism is often present in individual patients (9). Thus the effects of other influences, including decreased mobility and the production of tumor-associated cytokines other than PTH-rP are likely to be at least partly responsible for the differences between hypercalcemia of malignancy and primary hyperparathyroidism. Further elucidation of the precise role of PTH-rP in hypercalcemia of malignancy awaits further study including the measurement of this tumor product in individual patients with this disorder.

\section{Acknowledgments}

The authors are grateful to Nancy Garrett for her expert secretarial assistance.

This work was supported by grant CA-40035 from the National Cancer Institute, AR-28149, and RR1305. B. F. Boyce is supported in part by grants from the Peel Medical Research Trust, England, The Royal College of Pathologists of Great Britain, and the McCunn Trust, Scotland.

\section{References}

1. Nordin, B. E. C. 1976. Calcium Phosphate and Magnesium Metabolism. Clinical Physiology and Diagnostic Procedures. Churchill Livingstone, Edinburgh.

2. Harinck, H. I. J., O. L. M. Bijvoet, A. S. T. Plantingh, J. Body, J. W. F. Elte, H. P. Sleeboom, J. Wildiers, and J. P. Neijt. 1987. Role of bone and kidney in tumor-induced hypercalcemia and its treatment with bisphosphonate and sodium chloride. Am. J. Med. 82:11331142.

3. Ralston, S. H., I. Fogelman, M. D. Gardner, F. J. Dryburgh, R. A. Cowan, and I. T. Boyle. 1984. Hypercalcemia of malignancy: evidence for a non-parathyroid agent with an effect on renal tubular handling of calcium. Clin. Sci. (Lond.). 66:187-191.

4. Percival, R. C., A. J. P. Yates, R. E. S. Gray, J. Galloway, K. Rogers, F. E. Neal, and J. A. Kanis. 1985. Mechanisms of malignant hypercalcemia in carcinoma of the breast. Br. Med. J. 291:776-779.

5. Stewart, A. F., R. Horst, L. J. Deftos, E. C. Cadman, R. Lang, and A. E. Broadus. 1980. Biochemical evaluation of patients with cancer-associated hypercalcemia: evidence for humoral and nonhumoral groups. $N$. Engl. J. Med. 303:1377-1383.

6. Rude, R. K., C. F. Sharp, R. S. Fredericks, S. B. Oldham, N. Elbaum, J. Link, L. Irwin, and F. R. Singer. 1981. Urinary and nephrogenous adenosine 3',5'-monophosphate in the hypercalcemia of malignancy. J. Clin. Endocrinol. Metab. 52:765-771.

7. McDonnell, G. D., C. R. Dunstan, R. A. Evans, J. N. Carter, E. Hills, S. Y. P. Wong, and D. R. McNeil. 1982. Quantitative bone histology in the hypercalcemia of malignant disease. J. Clin. Endocrinol. Metab. 55:1066-1072.

8. Stewart, A. F., A. Vignery, A. Silvergate, N. D. Ravin, V. Livolsi, A. E. Broadus, and R. Baron. 1982. Quantitative bone histomorphometry in humoral hypercalcemia of malignancy-uncoupling of bone cell activity. J. Clin. Endocrinol. Metab. 55:219-227.

9. Mundy, G. R., K. J. Ibbotson, and S. M. D'Souza. 1985. Tumor products and the hypercalcemia of malignancy. J. Clin. Invest. 76:391-395.

10. Powell, D., F. R. Singer, T. M. Murray, C. Minkin, and J. T. Potts. 1973. Nonparathyroid humoral hypercalcemia in patients with neoplastic diseases. $N$. Engl. J. Med. 289:176-181.

11. Simpson, E. L., G. R. Mundy, S. M. D'Souza, K. J. Ibbotson, R. Bockman, and J. W. Jacobs. 1983. Absence of parathyroid hormone messenger RNA in non-parathyroid tumors associated with hypercalcemia. N. Engl. J. Med. 309:325-330.

12. Strewler, G. J., R. D. Williams, and R. A. Nissenson. 1983.
Human renal carcinoma cells produce hypercalcemia in the nude mouse and a novel protein recognized by parathyroid hormone receptors. J. Clin. Invest. 71:769-774.

13. Stewart, A. F., K. L. Insogna, D. Goltzman, and A. E. Broadus. 1983. Identification of adenylate cyclase-stimulating activity and cytochemical glucose-6-phosphate dehydrogenase-stimulating activity in extracts of tumors from patients with humoral hypercalcemia of malignancy. Proc. Natl. Acad. Sci. USA. 80:1454-1458.

14. Rabbani, S. A., J. Mitchell, D. R. Roy, R. Kremer, H. P. J. Bennett, and D. Goltzman. 1986. Purification of peptides with parathyroid hormone-like bioactivity from human and rat malignancies associated with hypercalcemia. Endocrinology. 118:1200-1210.

15. Moseley, J. M., M. Kubota, H. Diefenbach-Jagger, R. E. H. Wettenhall, B. E. Kemp, L. J. Suva, C. P. Rodda, P. R. Ebeling, P. J. Hudson, J. D. Zajac, and T. J. Martin. 1987. Parathyroid hormonerelated protein purified from a human lung cancer cell line. Proc. Natl. Acad. Sci. USA. 84:5048-5052.

16. Suva, L. J., G. A. Winslow, R. E. H. Wettenhall, R. G. Hammonds, J. M. Moseley, H. Diefenbach-Jagger, C. P. Rodda, B. E. Kemp, H. Rodriguez, E. Y. Chen, P. J. Hudson, T. J. Martin, and W. I. Wood. 1987. A parathyroid hormone-related protein implicated in malignant hypercalcemia: cloning and expression. Science (Wash. DC). 237:893-896.

17. Burtis, W. J., T. Wu, C. Bunch, J. J. Wysobmerski, K. L. Insogna, E. C. Weir, A. E. Broadus, and A. F. Stewart. 1987. Identification of a novel 17,000 dalton parathyroid hormone-like adenylate cyclase-stimulating protein from a tumor associated with humoral hypercalcemia of malignancy. J. Biol. Chem. 262:7151-7156.

18. Stewart, A. F., T. Wu, D. Goumas, W. J. Burtis, and A. E. Broadus. 1987. N-terminal amino acid sequence of two novel tumorderived adenylate cyclase-stimulating proteins: identification of parathyroid hormone-like and parathyroid hormone-unlike domains. Biochem. Biophys. Res. Commun. 146:672-678.

19. Strewler, G. J., P. H. Stern, J. W. Jacobs, J. Eveloff, R. F. Klein, S. C. Leung, M. Rosenblatt, and R. A. Nissenson. 1987. Parathyroid hormone-like protein from human renal carcinoma cells: structural and functional homology with parathyroid hormone. J. Clin. Invest. 80:1803-1807.

20. Hodges, R. S., and R. B. Merrifield. 1975. Monitoring of solid phase peptide synthesis by an automated spectrophotometric picrate method. Anal. Biochem. 65:241-272.

21. Gutierrez, G. E., G. R. Mundy, and M. S. Katz. 1986. Alterations in hormone sensitive adenylate cyclase of cloned rat osteosarcoma cell during long-term culture. J. Bone Miner. Res. 1:319-326.

22. Gutierrez, G. E., G. R. Mundy, and M. S. Katz. 1984. Adenylate cyclase of osteoblast-like cells from rat osteosarcoma is stimulated by calcitonin as well as parathyroid hormone. Endocrinology. 115:2342-2346.

23. Morel, F., D. Chabardes, and M. Imbert-Teboul. 1978. Methodology for enzymatic studies of isolated tubular segments. Methods Pharmacol. 4B:297-323.

24. Raisz, L. G. 1965. Bone resorption in tissue culture. Factors influencing the response to parathyroid hormone. J. Clin. Invest. 44:103-116.

25. Brooker, G., W. L. Terasaki, and M. G. Price. 1976. Gammaflow: a completely automated radioimmunoassay system. Science (Wash. DC). 194:270-276.

26. Brooker, G., J. F. Harper, W. L. Terasaki, and R. D. Moylan. 1979. Radioimmunoassay of cyclic AMP and cyclic GMP. Adv. Cyclic Nucleotide Res. 10:1-33.

27. Chabardes, D., M. Imbert, A. Clique, M. Montegut, and F. Morel. 1975. PTH-sensitive adenyl cyclase activity in different segments of rabbit nephron. Pflügers Arch. Eur. J. Physiol. 354:229-239.

28. Hock, J. M., H. A. Simmons, M. C. Schiess, and L. G. Raisz. 1982. Use of osmotic minipumps for delivery of parathyroid hormone. Calcif. Tissue Int. 34:270-272.

29. Sabatini, M., B. Boyce, and G. Mundy. 1987. Recombinant human interleukin-1 beta infusions cause hypercalcemia and stimulate bone resorption in vivo. J. Bone Miner. Res. 2(Suppl. 1):386. (Abstr.) 